\title{
The Pressure Gradient across the Endocardium
}

\author{
Rachad Mounir Shoucri \\ Royal Military College of Canada, Kingston, Ontario
}

\begin{abstract}
A mathematical formalism for the non-linear endsystolic pressure-volume relation (ESPVR) in the heart ventricles has the interesting feature that the peak active pressure generated by the myocardium (also called peak isovolumic pressure $P_{\text {isom }}$ by physiologists) is included in the mathematical formalism describing the ESPVR. In this study we look at the ratio $\left(P_{\text {isom }}-P_{m}\right) / P_{m}$ as an index to segregate between different clinical groups, this ratio can be calculated in a non-invasive way with the mathematical model used. Application to the left ventricle by using clinical data taken from the medical literature is given and discussed. Mathematical relations between the ejection fraction (EF) and the parameters describing the ESPVR are used in a way to get new insight into the problem of heart failure with normal or preserved ejection fraction ( $\mathrm{HFPEF}$ ).
\end{abstract}

\section{Introduction}

The end-systolic pressure-volume relation (ESPVR) is the relation between pressure and volume in the left or right ventricle when the myocardium reaches its maximum state of activation during the contraction phase, possible clinical application of this relation has been extensively studied [1-10]. The mathematical model used in this study has been derived in previous publications [810], it is based on the theory of large elastic deformation of the myocardium. An interesting feature of this model is the introduction of the peak active force generated by the myocardium in the mathematical formalism describing the non-linear ESPVR. When inertia forces and viscous forces are neglected, the peak active force generated by the myocardium can be equated to the peak isovolumic pressure $\mathrm{P}_{\text {isom }}$ generated by the myocardium in a non-ejecting contraction. Non-invasive calculation of the ratio $\left(\mathrm{P}_{\text {isom }}-\mathrm{P}_{\mathrm{m}}\right) / \mathrm{P}_{\mathrm{m}}$ is possible with the mathematical formalism used, and in this study we show how this ratio can be used for the purpose of segregation and classification of different clinical groups. This index can be related to the study of the problem of heart failure (HF) with normal or preserved ejection (HFpEF) as will be indicated, HFpEF is defined as HF with EF > 0.5 [7].
In what follows we first review the mathematical formalism used, then we present some applications to clinical data published in the literature [11-14]. The mathematical formalism applies to the right and left ventricle (LV), we restrict our discussion in what follows to the LV. Previous applications of the mathematical formalism to a wide range of clinical data have shown the consistency of the mathematical formalism used [8-10, and references given therein].

\section{Mathematical formalism}

The left ventricle is represented as a thick-walled cylinder contracting symmetrically [8-10] (see Fig. 1). During the contraction phase, the myocardium generates a radial active force per unit volume of the myocardium designated by $\mathrm{D}_{\mathrm{r}}$, which force will develop an active pressure $\int_{a}^{b} D_{r} d r \approx P_{\text {iso }}$ on the inner surface of the myocardium (endocardium), $\mathrm{a}=$ inner radius, $\mathrm{b}=$ outer radius, $\mathrm{h}=\mathrm{b}-\mathrm{a}=$ thickness of the myocardium. In $\mathrm{a}$ quasi-static approximation (inertia and viscous forces neglected), the equilibrium of forces on the endocardium can be expressed in the form

$$
\mathrm{P}_{\text {iso }}-\mathrm{P}=\mathrm{E}_{2}\left(\mathrm{~V}_{\text {ed }}-\mathrm{V}\right)
$$

$\mathrm{P}$ is the $\mathrm{LV}$ pressure, $\mathrm{V}$ the $\mathrm{LV}$ volume and it is indicated as $V_{\text {ed }}$ at end-diastole (when $d V / d t=0$ ), $E_{2}$ is an elastance coefficient that relates the difference of pressures $\mathrm{P}_{\text {iso }}-\mathrm{P}$ to the difference of volumes $V_{\text {ed }}-V$. Near end-systole when the myocardium reaches its maximum state of activation, Eq. (1) can be expressed in the form

$$
\mathrm{P}_{\text {isom }}-\mathrm{P}_{\mathrm{m}}=\mathrm{E}_{2 \mathrm{~m}}\left(\mathrm{~V}_{\text {ed }}-\mathrm{V}_{\mathrm{m}}\right)
$$

$\mathrm{V}_{\mathrm{m}} \approx \mathrm{V}_{\text {es }}\left(\mathrm{V}_{\text {es }}\right.$ the end-systolic volume when $\left.\mathrm{dV} / \mathrm{dt}=0\right)$, $\mathrm{P}_{\text {isom, }} \mathrm{P}_{\mathrm{m}}$, and $\mathrm{V}_{\mathrm{m}}$ are as defined in Eq. (1) but measured at the moment when the myocardium reaches its maximum state of activation. Figure 2 represents a non-linear ESPVR shown as the curve BDC, it is the relation obtained when $\mathrm{P}_{\mathrm{m}}$ and $\mathrm{V}_{\mathrm{m}}$ are varied and the peak isovolumic pressure $\mathrm{P}_{\text {isom }}$ is kept constant (as if a balloon is inflated against a constant $\mathrm{P}_{\text {isom }}$ ). From Fig.2, $\mathrm{E}_{2 \mathrm{~m}}=$ $\tan \beta_{2}$ corresponds to the slope of the line CD that 
intersects the volume axis at a point indicated as $\mathrm{V}_{02}$.

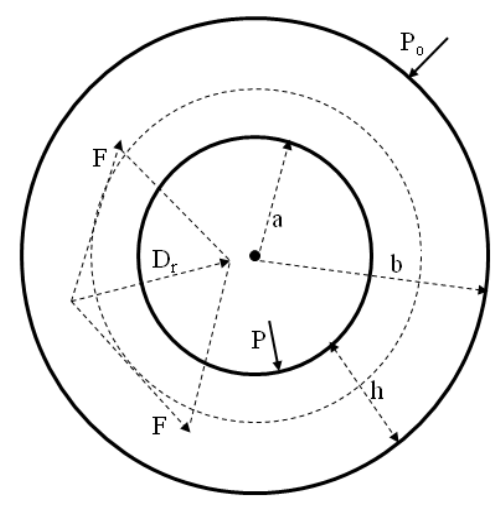

Figure 1: Cross-section of a thick-walled cylinder representing the left ventricle, $D_{r}=$ active radial force/unit volume of the myocardium, $\mathrm{P}=$ left ventricular pressure, $\mathrm{P}_{0}=$ outer pressure (assumed zero) on the myocardium, $\mathrm{a}=$ inner radius, $\mathrm{b}=$ outer radius, $\mathrm{h}=\mathrm{b}-\mathrm{a}=$ thickness of the myocardium.

When the left ventricular pressure $\mathrm{P}_{\mathrm{m}} \rightarrow 0$, we have $\mathrm{V}_{\mathrm{m}}$ $\rightarrow \mathrm{V}_{\mathrm{om}}$ in Eq. (2), and we get

$$
\mathrm{P}_{\text {isom }}=\mathrm{E}_{\mathrm{m}}\left(\mathrm{V}_{\text {ed }}-\mathrm{V}_{\text {om }}\right)
$$

$\mathrm{E}_{\mathrm{m}}=\tan \alpha$ is the slope of the line CB in Fig. 2, and $\mathrm{V}_{\mathrm{om}}$ corresponds to the intercept with the volume axis at point $\mathrm{B}$ of the curve BDC. The tangent (with slope tan $\gamma$ ) at point $\mathrm{D}$ to the curve BDC intersects the volume axis at a point corresponding to $\mathrm{V}_{\text {ot. }}$. The line $\mathrm{BD}$ has slope $\tan \beta_{1}$ as shown in Fig. 2. From trigonometric relations between the triangles one can derive (see also [8])

$$
\begin{aligned}
& \tan \gamma / \mathrm{e}_{\mathrm{am}}=\mathrm{SV} /\left(\mathrm{V}_{\mathrm{m}}-\mathrm{V}_{\mathrm{ot}}\right)=\left(\mathrm{P}_{\mathrm{t}}-\mathrm{P}_{\mathrm{m}}\right) / \mathrm{P}_{\mathrm{m}} \\
& \tan \beta_{2} / \mathrm{e}_{\mathrm{am}}=\mathrm{SV} /\left(\mathrm{V}_{\mathrm{m}}-\mathrm{V}_{\mathrm{o} 2}\right)=\left(\mathrm{P}_{\text {isom }}-\mathrm{P}_{\mathrm{m}}\right) / \mathrm{P}_{\mathrm{m}} \\
& \tan \beta_{1} / \mathrm{e}_{\mathrm{am}}=\mathrm{SV} /\left(\mathrm{V}_{\mathrm{m}}-\mathrm{V}_{\mathrm{om}}\right)=\left(\mathrm{P}_{\mathrm{s}}-\mathrm{P}_{\mathrm{m}}\right) / \mathrm{P}_{\mathrm{m}}
\end{aligned}
$$

$\mathrm{P}_{\mathrm{s}}$ is not shown in Fig. 2, and $\mathrm{e}_{\mathrm{am}}=\mathrm{P}_{\mathrm{m}} / \mathrm{SV}$ is the arterial elastance. From Eqs (4) the stroke volume $\mathrm{SV} \approx \mathrm{V}_{\text {ed }}-\mathrm{V}_{\mathrm{m}}$ (and consequently $\mathrm{EF}=\mathrm{SV} / \mathrm{V}_{\mathrm{ed}}$ ) are related to the slopes describing the curve BDC, and to the intercepts $\mathrm{V}_{\mathrm{ot}}, \mathrm{V}_{\mathrm{o}}$, and $\mathrm{V}_{\text {om }}$ shown in Fig. 2 and in Eqs. (4).

\section{Criteria of $\mathrm{LV}$ performance}

For simplicity we assume that $\mathrm{P}_{\mathrm{m}}$ is constant during the contraction phase. When the point $\mathrm{D}$ on the ESPVR moves on the curve $\mathrm{BDC}$, the stroke work $\mathrm{SW} \approx \mathrm{P}_{\mathrm{m}} \mathrm{SV}$ reaches its maximum value $S_{\mathrm{x}}$ when the derivative $\mathrm{d}(\mathrm{SW}) / \mathrm{dV}_{\mathrm{m}}$ is zero. Simple calculation as in [8] gives

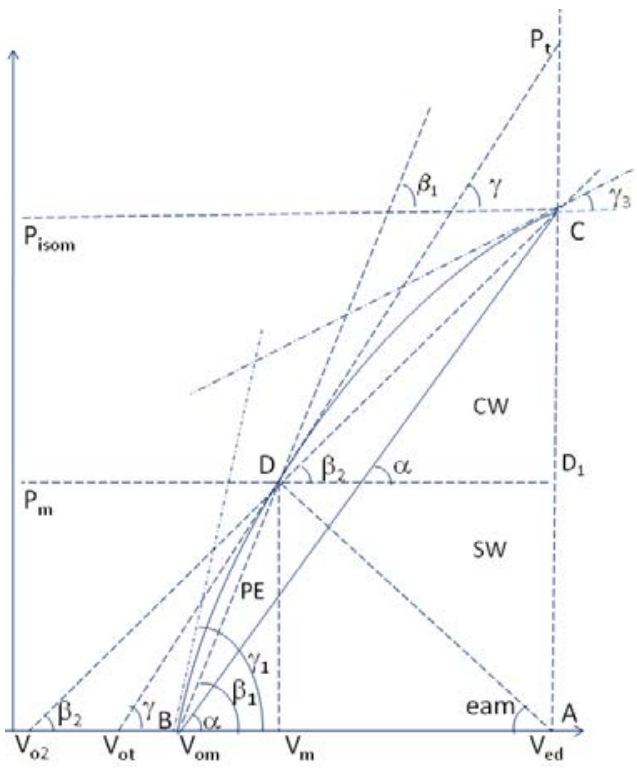

Figure 2: ESPVR represented by the curve BDC, intercept with the horizontal volume axis is $\mathrm{B}$ (corresponding to $\mathrm{V}_{\mathrm{om}}$ ). Stroke work $\mathrm{SW} \approx$ area $\mathrm{AD}_{1} \mathrm{DV} \mathrm{m}, \mathrm{PE}=$ area determined by $\operatorname{arc}(\mathrm{BD}) \mathrm{V}_{\mathrm{mB}}, \mathrm{CW}=$ area determined by $\operatorname{arc}(\mathrm{DC}) \mathrm{D}_{1} \mathrm{D}$. TW $=\mathrm{CW}$ $+\mathrm{SW}+\mathrm{PE}$ is total area under the ESPVR. Ventricular pressure $\mathrm{P}_{\mathrm{m}}, \mathrm{P}_{\text {isom }}$ is the peak isovolumic pressure. $\mathrm{V}_{\text {ot }}$ corresponds to the intercept with the volume axis of the tangent (with slope tan $\gamma$ ) at point $\mathrm{D}, \mathrm{V}_{\mathrm{o} 2}$ corresponds to the intercept of the line $\mathrm{CD}$ (with slope $\tan \beta_{2}$ ) with the volume axis; $e_{a m}=P_{m} / S V$ is the arterial elastance.

$$
\tan \gamma=\mathrm{e}_{\mathrm{am}} \quad \text { and } \quad \mathrm{SV}=\mathrm{V}_{\mathrm{m}}-\mathrm{V}_{\mathrm{ot}}
$$

or equivalently $\mathrm{V}_{\mathrm{m}}=\left(\mathrm{V}_{\text {ed }}+\mathrm{V}_{\mathrm{ot}}\right) / 2$. The stroke work reserve SWR is defined as

$$
\mathrm{SWR}=\mathrm{SW}_{\mathrm{x}}-\mathrm{SW}
$$

SWR can be considered as a measure of the amount by which the energy SW delivered to the systemic load can increase. Consequently one can distinguish the following criteria of performance for the left ventricle:

a) $\mathrm{SW}<\mathrm{SW}_{\mathrm{x}}$ and $\mathrm{SV}>\left(\mathrm{V}_{\mathrm{m}}-\mathrm{V}_{\mathrm{ot}}\right)$, with $\tan \gamma>\mathrm{e}_{\mathrm{am}}$. In this case an increase in the afterload $\mathrm{P}_{\mathrm{m}}$ results in an increase in SW as expected, a normal state of the left ventricle.

b) $\mathrm{SW}=\mathrm{SW}_{\mathrm{x}}$ and $\mathrm{SV}=\left(\mathrm{V}_{\mathrm{m}}-\mathrm{V}_{\mathrm{ot}}\right)$, with $\tan \gamma=\mathrm{e}_{\mathrm{am}}$ and $\mathrm{SWR}=0$. In this case an increase in afterload $\mathrm{P}_{\mathrm{m}}$ results in a mild decrease in SW causing cardiac insufficiency.

c) $\mathrm{SW}<\mathrm{SW}_{\mathrm{x}}$ and $\mathrm{SV}<\left(\mathrm{V}_{\mathrm{m}}-\mathrm{V}_{\mathrm{ot}}\right)$, with $\tan \gamma<\mathrm{e}_{\mathrm{am}}$. In this case an increase in afterload $\mathrm{P}_{\mathrm{m}}$ results in a severe decrease in SW causing severe cardiac insufficiency.

Experimental verification of these results can be found for the LV in [4,5], and for the right ventricle in [6]. 


\section{Applications to clinical data}

Figure 3 shows some clinical results verifying the results of the preceding discussion. It is calculated by using clinical data taken from from Azancot el al [11].
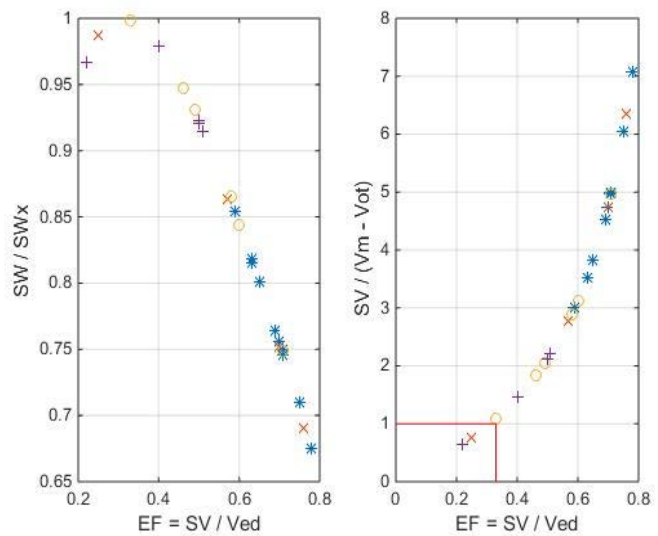

Figure 3: (right) Relation shows that for $\mathrm{SV} /\left(\mathrm{V}_{\mathrm{m}}-\mathrm{V}_{\mathrm{ot}}\right) \approx 1$ we have $\mathrm{EF} \approx 0.33$; (left) Relation shows that for $\mathrm{EF} \approx 0.33$ we have $\mathrm{SW} / \mathrm{SWx} \approx 1$; normal $*$, hypertrophy $\mathrm{x}$, dilated $\mathrm{MC}+$, volume overload o. Data taken from Azancot et al [11].

The right side of Fig. 3 shows that for the critical value of $\mathrm{SV} /\left(\mathrm{V}_{\mathrm{m}}-\mathrm{V}_{\mathrm{ot}}\right) \approx 1$ we have a value for $\mathrm{EF} \approx 0.33$, which corresponds to $\mathrm{SW} / \mathrm{SWx} \approx 1$ as seen on the left side. From Fig. 4 we see that for $\mathrm{SW} / \mathrm{SWx} \approx 1$ we have
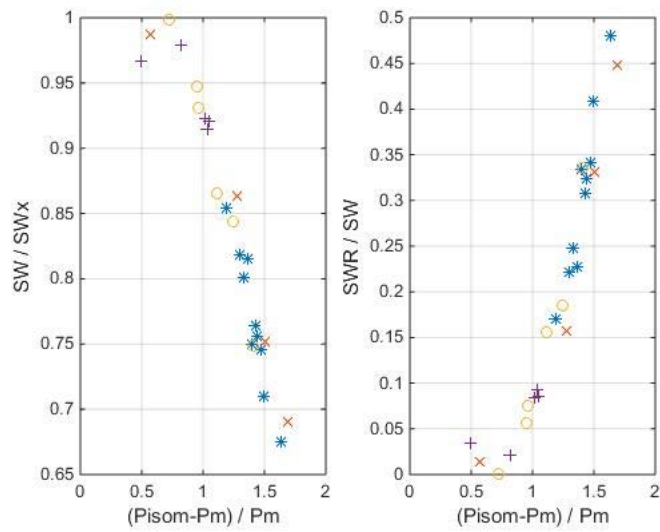

Figure 4: (left) Relation shows $\left(\mathrm{P}_{\text {isom }}-\mathrm{P}_{\mathrm{m}}\right) / \mathrm{P}_{\mathrm{m}} \approx 0.6$ for $\mathrm{SW} / \mathrm{SW}_{\mathrm{x}} \approx 1$; (right) Relation shows that for $\left(\mathrm{P}_{\text {isom }}-\mathrm{P}_{\mathrm{m}}\right) / \mathrm{P}_{\mathrm{m}} \approx$ 0.6 we have $\mathrm{SWR} / \mathrm{SW} \approx 0$; normal *, hypertrophy $\mathrm{x}$, dilated $\mathrm{MC}$ + , volume overload o. Data taken from Azancot et al [11].

$\mathrm{SWR} / \mathrm{SW} \approx 0$ and $\left(\mathrm{P}_{\text {isom }}-\mathrm{P}_{\mathrm{m}}\right) / \mathrm{P}_{\mathrm{m}} \approx 0.6$.

We have used another group of clinical data obtained from echocardiography measurements on five groups of patients taken from [12]. The relation between percentage of HF and EF was taken from [13] and it is reproduced in Fig. 5 (left side). The least square fit curve shown on the left side of Fig. 5 was calculated and used to derive the relation between percentage of $\mathrm{HF}$ and $\mathrm{EF}$ for data taken from [12] as shown on the right side of Fig. 5. Note in
Fig. 5 (right side) that the normal group $(*)$ appears around the minimum of the curve, with $\mathrm{EF} \approx 0.67$.
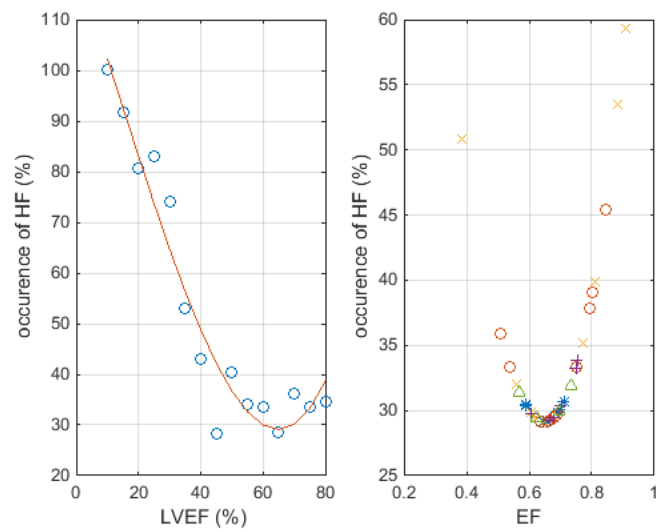

Figure 5: (left) Relation between percentage of $\mathrm{HF}$ and percentage of left ventricular EF, least square fit is used to calculate the right side, data from [13]; (right) Relation between percentage of HF and EF for five clinical groups; normal *, aortic stenosis 0 , aortic valvular regurgitation + , mitral regurgitation $\wedge$, miscellaneous cardiomyopathies $\mathrm{x}$. Data from Dumesnil et al [12].
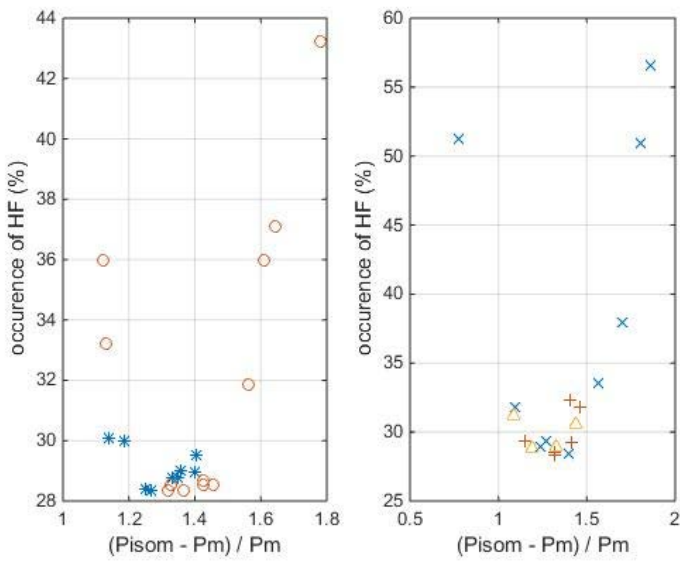

Figure 6: Relation between $\left(\mathrm{P}_{\text {isom }}-\mathrm{P}_{\mathrm{m}}\right) / \mathrm{P}_{\mathrm{m}}$ and percentage of $\mathrm{HF}$, normal * and aortic stenosis o, on the left side; on the right side aortic valvular regurgitation + , mitral regurgitation $\wedge$, miscellaneous cardiomyopathies x,. Data from Dumesnil et al.

From Eq (4b) and the least square fit shown in Fig 5 (left), the relation between $\left(\mathrm{P}_{\text {isom }}-\mathrm{P}_{\mathrm{m}}\right) / \mathrm{P}_{\mathrm{m}}$ and the percentage of HF is calculated in Fig. 6. We have shown separately on the left side the normal group $(*)$, and the aortic stenosis group (o) for the purpose of clarity. Note the minimum observed for $\left(\mathrm{P}_{\text {isom }}-\mathrm{P}_{\mathrm{m}}\right) / \mathrm{P}_{\mathrm{m}} \approx 1.33$ in Fig. 6. Note also in Fig. 6 (left) that only part of the group of aortic stenosis overlaps with the normal group, a similar observation applies to the right side of Fig. 6 .

Figure 7 compares results for aortic stenosis (o) with the normal group $(*)$. One can observe three apparent groupings of the data of aortic stenosis:

a) a grouping with low $\left(\mathrm{P}_{\text {isom }}-\mathrm{P}_{\mathrm{m}}\right) / \mathrm{P}_{\mathrm{m}}$ corresponding to low EF but high SW/TW, indicating low values of TW 

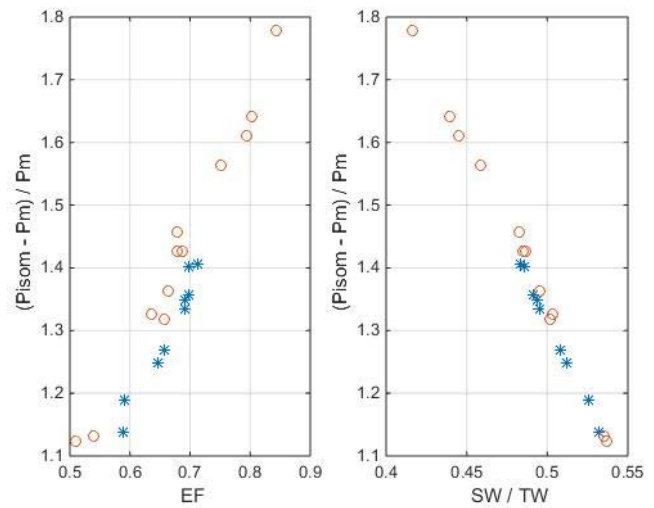

Figure 7: (left) Relation between $\left(\mathrm{P}_{\text {isom }}-\mathrm{P}_{\mathrm{m}}\right) / \mathrm{P}_{\mathrm{m}}$ and EF; (right) Relation between $\left(\mathrm{P}_{\text {isom }}-\mathrm{P}_{\mathrm{m}}\right) / \mathrm{P}_{\mathrm{m}}$ and SW/TW; normal group $*$, aortic stenosis o. Note the three groupings for cases of aortic stenosis.

and $\mathrm{P}_{\text {isom, }}$ and possible depressed state of the myocardium. One can assume that the total area TW under the ESPVR reflects the total energy needed by the LV (including the myocardium) to perform its function.

b) A grouping around the normal group, with $\left(\mathrm{P}_{\text {isom }}-\right.$ $\left.\mathrm{P}_{\mathrm{m}}\right) / \mathrm{P}_{\mathrm{m}} \approx 1.33$ corresponding to $\mathrm{EF} \approx 0.67$ and $\mathrm{SW} / \mathrm{TW} \approx$ $0.5(\mathrm{SW} / \mathrm{TW}=$ stroke work/total area under ESPVR).

c) A grouping with high $\left(\mathrm{P}_{\text {isom }}-\mathrm{P}_{\mathrm{m}}\right) / \mathrm{P}_{\mathrm{m}}$ corresponding to high EF but low SW/TW, indicating high values for TW and $\mathrm{P}_{\text {isom, }}$ corresponding to a possible case of hypertension (and possibly high resistance to aortic flow).

\section{Discussion}

A Numerical calculation of the values of $\mathrm{V}_{\text {om }}, \mathrm{V}_{\text {ot }}$, and $\mathrm{V}_{02}$ (see Fig. 2) allows the calculation of several parameters of the curve BDC representing the ESPVR, from which important indexes can be derived like in Eqs. (4). In this study we have given special attention to the non-invasive calculation of $\left(\mathrm{P}_{\text {isom }}-\mathrm{P}_{\mathrm{m}}\right) / \mathrm{P}_{\mathrm{m}}$ by using Eq. (4b), results of application of this index to clinical data have been presented in Figs 3 to 7 that show that bivariate (and possibly multivariate) analysis of data is superior to univariate analysis of data (like by using only EF). Figures 5 to 7 show that cases of HFpEF appear with values of $\mathrm{EF}>(\mathrm{EF}$ for normal group $(*))$. Further assessment of these results requires an invasive measurement of the ventricular pressure $\mathrm{P}_{\mathrm{m}}$.

\section{Conclusion}

The curve showing the percentage variation of HF can be implemented for routine clinical work in a noninvasive way with several indexes derived from the ESPVR, when ratios of pressures and areas are calculated. EF appears as one index of several indexes that can be applied for non-invasive routine clinical work.

\section{References}

[1] C Burkhoff D, Mirsky I, Suga H. Assessment of systolic and diastolic ventricular properties via pressure-volume analysis; a guide for clinical, translational, and basic researchers. Am J Physiol Hear Circ 2005; 289: H501-12.

[2] Ochagavia A, Zapata L, Carrillo A, Rodriguez A, Guerrero M, Ayuela LM. Evaluation of contractility and postloading in the intensive care unit. Medicina Intensiva 2012; 36(5): 365-74.

[3] Blaudszun G, Morel DR. Relevance of the volume-axis intercept, $V_{0}$, compared with the slope of the end-systolic pressure-volume relationship in response to large variations in inotropy and afterload in rats. Exp Physiol 2011, 96: 1179-95.

[4] Burkhoff D, Sagawa K. Ventricular efficiency predicted by an analytical model. Am J Physiol 1989; 250: R1021-27.

[5] Asanoi H, Sasayama S, Kameyama T. Ventriculoarterial coupling in normal and failing heart in humans.Circ Res 1989, 65: 91-8.

[6] Brimioulle S, Waulthy P, Ewalenko P, Rondelet B, Vermeulen F, Kerbaul F, Naeije R. Single-beat estimation of the right ventricular end-sytolic pressure-volume relationship. Am J Physiol Heart Circ 2003, 284: H1625-30

[7] Najjar S. Heart failure with preserved ejection fraction. J. Am Coll Cardiol 2009; 54: 419-21.

[8] Shoucri RM. End-Systolic Pressure-Volume Relation, Ejection Fraction, and Heart Failure: Theoretical Aspect and Clinical Applications. Clinical Medicine Insights: Cardiology 2015; 9(S1): 111-20.

[9] Shoucri RM. Heart Failure, End-Systolic Pressure-Volume Relation. Computing in Cardiology (Nice, France) 2015; 242-45.

[10] Shoucri RM. ESPVR, ejection fraction and heart failure. Cardiovasc Eng. 2010; 10: 207-12.

[11] Azancot I, Masquet C, Bourthoumieux, Georgiopoulos G, Slama R, Boubrain Y. Myocardial hypertrophy, rate of change, of free wall thickness and directional components of ventricular power in man. J Physiol (Paris) 1981; 65: 9198.

[12] Dumesnil JG, Shoucri RM, Laurenceau JL, Turcot J. A mathematical model of the dynamic geometry of the intact left ventricle and its application to clinical data. Circulation 1979; 59: 1024-34.

[13] Da Mota JPGF, Intelligent modeling to predict ejection fraction from echocardiographic reports. MSc thesis in Mech Eng, IST Técnico Lisboa, Portugal, Nov 2013.

[14] Curtis JP, Sokol SI, Wang Y, Rathore SS, Ko DT, et al. The association of left ventricular ejection fraction, mortality, and cause of death in stable outpatients with heart failure. J Am Coll Cardiol 2003; 42 (3): 736-42.

Address for correspondence.

Rachad Mounir Shoucri

Department of Mathematics and Computer Science

Royal Military College of Canada, Kingston, Ontario, K7K 7B4 shoucri-r@rmc.ca 